\title{
Políticas Públicas em Saúde Mental e Trabalho: Desafios Políticos e Epistemológicos
}

\author{
Public Policies In Mental Health And Work: \\ Political And Epistemological Challenges \\ Políticas Públicas En Salud Mental Y Trabajo: \\ Desafíos Políticos Y Epistemológicos
}
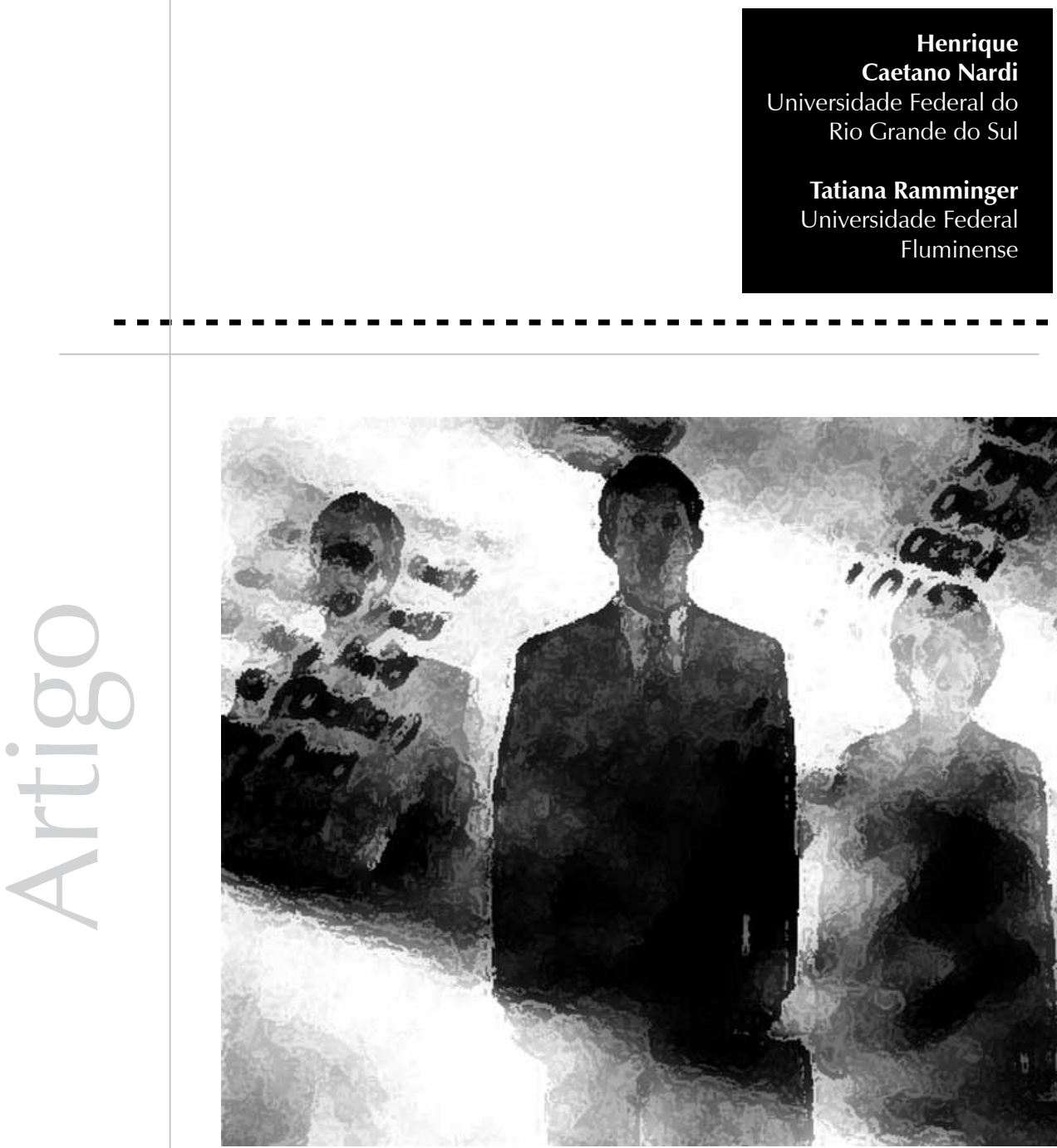
Resumo: O objetivo deste artigo é buscar compreender, a partir da perspectiva genealógica, as possibilidades de emergência dos enunciados que delimitam a relação entre Saúde Mental e trabalho e sua (des)articulação com as políticas de saúde do trabalhador. Como forma de apontar essas articulações e desarticulações, partimos de uma breve descrição analítica das Conferências Nacionais Brasileiras de Saúde do Trabalhador. Como hipóteses para a compreensão dos impasses para efetivar essa articulação, apresentamos os desafios políticos e epistemológicos que atravessam as formas de legitimação dos saberes-verdades nos campos da Saúde do Trabalhador e da Saúde Mental.

Palavras-chave: Saúde ocupacional. Saúde Mental. Políticas públicas.

\begin{abstract}
This article searches to understand, based on a genealogical approach, the possibilities for the emergence of the statements that demarcate the field of mental health and is (dis)articulation with workers' health policies. As a way to point out the articulations and disarticulations between these policies and its programmatic instruments, we will present a brief analytical description of the national conferences that dealt with these themes. As a comprehensive hypothesis for the obstacles for the implementation of this articulation, we will present the political and epistemological challenges of the knowledge-truth legitimating ways in the fields of mental health and workers' health.
\end{abstract}

Keywords: Occupationa health. Mental health. Public policies.

Resumen: El objetivos de este artículo es tratar de comprender, desde la perspectiva genealógica, las posibilidades de emergencia de los enunciados que delimitan la relación entre salud mental y trabajo y su (des)articulación con las políticas de salud del trabajador. Como forma de señalar esas articulaciones y desarticulaciones, partimos de una breve descripción analítica de las Conferencias Nacionales Brasileñas de Salud del Trabajador. Como hipótesis para la comprensión de los obstáculos para efectuar esa articulación, presentamos los desafíos políticos y epistemológicos que atraviesan las formas de legitimación de los saberesverdades en los campos de la salud del trabajador y de la salud mental.

Palabras clave: Salud ocupacional. Salud mental. Políticas públicas.

\title{
Campos conflituosos
}

Os campos da Saúde Mental e da Saúde do Trabalhador são arenas tensas de disputa política e epistemológica. O movimento da reforma sanitária, principalmente a partir da VIII Conferência Nacional de Saúde (1986), produziu uma revolução institucional e uma desacomodação dos saberes-verdades que estavam protegidos pela institucionalidade da tecnoburocracia criada pela ditadura militar. No caso da Medicina do Trabalho, seu reconhecimento oficial como saber legítimo para o cuidado da saúde dos trabalhadores - mediante as portarias que criaram as normas regulamentadoras - se deu nesse período e assumiu um modelo de atuação subordinado à lógica do Capital. A emergência da Medicina do Trabalho no Brasil se deu, portanto, a partir de uma forma autoritária de regulação das relações entre trabalhadores e empresários.

No que tange à Saúde Mental, os anos de chumbo foram aqueles do império dos manicômios, caracterizados pela superpopulação e pela reificação dos portadores de sofrimento psíquico. As práticas desrespeitadoras dos direitos humanos legitimadas nos grandes depósitos de loucos eram sustentadas por um modelo psiquiátrico autoritário e perverso associado a um Estado que não hesitava em aprisionar nos manicômios todas as apresentações da subjetividade consideradas desviantes ou contestatórias.

A redemocratização do sistema de saúde foi marcada por uma aliança de trabalhadores/ as da saúde, sindicalistas, operários/as, donas de casa, religiosos/as, agricultores/as sem terra, familiares de portadores de sofrimento psíquico e pesquisadores/as, entre outros, que, a partir do estabelecimento de um conceito de saúde revolucionário, denunciavam a crueldade das formas de assujeitamento que se legitimavam em determinados saberes e práticas autoritários. Não nos cabe aqui 
1 Ao usarmos o termo institucionalização, fazemos aqui uma aproximação conceitual com as distinções propostas pela análise institucional (AI), para a qual o instituinte é um processo produtivo-desejante, de característica dinâmica, enquanto o instituído é o resultado desse processo e tem características estáticas e estáveis, além de resistir a mudanças em razão da cristalização das relações de poder. Nessa direção, podemos considerar o Movimento da Reforma Sanitária como um processo instituinte e apontar os riscos de o SUS se tornar progressivamente resistente ao movimento a partir de sua progressiva burocratização e institucionalização (Baremblitt, 1998). retomar em detalhe o amplo e complexo debate político e epistemológico desse primeiro período de afirmação da Reforma Sanitária e de institucionalização do Sistema Único de Saúde, uma vez que estaríamos repetindo muito do já dito pela extensa produção histórica e científica do período (Cohn, 1980; Dias, 1994; Luz, 1984; Possas, 1989; Selligmann-Silva, 1994; Teixeira, 1989; Vilaça Mendes, 1993).

Mais de 20 anos se passaram desde a VIII Conferência Nacional de Saúde e das primeiras Conferências Nacionais de Saúde do Trabalhador e de Saúde Mental. Essas políticas programáticas apresentam hoje um alto grau de institucionalização ${ }^{1}$, mas muitos desafios antigos persistem e novos se apresentam. O termo movimento, que antecede a expressão reforma sanitária, é de fundamental importância para pensarmos sobre os processos em curso, pois o SUS e seus programas específicos estão em permanente transformação e não há garantia de estabilidade em relação aos avanços políticos e científicos dos últimos anos. As resistências conservadoras presentes nos jogos de saber e poder dos campos da Saúde Mental e da Saúde do Trabalhador estão bem presentes no cotidiano, seja pelo retorno de velhas práticas, seja pela desmobilização política e por um novo desequilíbrio de forças entre o Capital e o Trabalho, ou ainda, pela persistência dos manicômios mentais e das formas autoritárias das relações de trabalho que, ancoradas em uma sociedade estruturalmente desigual, produzem formas naturalizadas de desrespeito ao outro como igual em direitos e marcadas pela subalteridade própria às sociedades póscoloniais (Bhabha, 1998).

Cabe ainda ressaltar, nesta escrita introdutória, a dificuldade de estabelecermos áreas de confluência entre os programas setoriais da Saúde Mental e da saúde do trabalhador. Ambos os programas se conformaram de forma diferenciada à estrutura hierarquizada do SUS, uma vez que optaram por centros de referência especializados como ordenadores da rede de Saúde Mental e de saúde do trabalhador, quais sejam, os CAPS - Centros de Atenção Psicossocial - e os CRST - Centros de Referência em Saúde do Trabalhador, respectivamente. Hoje a Saúde Mental busca sua inserção na atenção básica, enquanto a Saúde do Trabalhador se mantém distanciada da porta de entrada do SUS, reproduzindo as mesmas características de quando tinha uma entrada privilegiada no sistema de assistência para os trabalhadores, nos extintos INPS/INAMPS. Essa forma diferenciada de implantar a atenção pode nos ajudar a compreender porque a discussão relativa às ações no campo da Saúde Mental não se acha incorporada na política de saúde do trabalhador, e vice-versa.

A forma como as políticas públicas se debruçam sobre o tema da Saúde Mental dos trabalhadores nos remete às clássicas questões que definem como operam as políticas, ou seja: quem obtém o que, quando e como? As políticas definem os direitos e a forma de torná-los efetivos, definem os conteúdos da cidadania e as questões que são meritórias de ações do Estado. Assim, ao pensarmos na promoção da Saúde Mental dos trabalhadores, devemos nos perguntar se essa é uma questão politicamente importante para o Estado e qual a compreensão de Saúde Mental que guia as práticas de governo.

Trata-se também de compreender, no jogo de forças entre o Capital e o Trabalho, como o Estado intervém no embate entre as políticas sociais e as políticas econômicas que regem a governabilidade neoliberal (Lemke, 2001). É importante lembrar que toda política contribui para a transformação ou para a reprodução da ordem social, assim, a ausência de programas e políticas também deve ser compreendida como um posicionamento do Estado (Pecheny \& Dehesa, 2009). 
2 A Psicologia ocupa um campo teórico e epistemológico amplo,

e, certamente, não estamos aqui restringindo sua ação ao campo da saúde, pois sua origem e inserção se dão também no campo das ciências humanas, entretanto, é sua inserção na saúde que está sendo discutida aqui.

3 Cabe lembrar que as profissões na área da saúde não se restringem a essas (segundo o Ministério da Educação, são 14 profissões regulamentadas na área da saúde), sendo que aqui se citou apenas aquelas profissões que mais se destacam no campo da saúde do trabalhador.

4 A ergonomia, principalmente na sua vertente francesa, incorpora diversos elementos da Sociologia do trabalho, sendo também um campo difícil de restringir às clássicas divisões disciplinares.

\section{Questões epistemológicas presentes na articulação Saúde Mental e saúde do trabalhador}

As temáticas da saúde do trabalhador, da Saúde Mental e da subjetividade são indissociáveis tanto do ponto de vista teórico como do exercício da pesquisa e da intervenção. A compreensão da articulação entre saúde, subjetividade e trabalho demanda um movimento teórico e uma ação interdisciplinares. Ou ainda, como afirma Foucault (1994), deve-se buscar o desdisciplinamento dos objetos, dos problemas, dos sistemas, das estruturas, das práticas e dos discursos que foram forjados e construídos com base em um modelo disciplinar, na construção do projeto de ciência da modernidade na sua articulação com o campo institucional. Isso significa que o desafio fundamental não consiste somente em aproximar as disciplinas e seus saberes, uma vez que esses saberes foram construídos a partir de uma base disciplinar comum, mas em se evidenciar as lógicas de produção dos discursos e, utilizando a perspectiva da genealogia, compreender o modo como estes conformaram os objetos que estudam e sobre os quais intervêm.

Considerando esse ponto de partida, o movimento sanitário/político da saúde do trabalhador, tal como construído no Brasil, a partir de sua inspiração no movimento operário italiano e dentro do bojo da reforma sanitária, traz, nos seus enunciados/princípios, um elemento de diferenciação essencial que propõe como ideal o desdisciplinamento da compreensão do objeto/sistema complexo das relações entre saúde e trabalho. Esse diferencial se torna evidente na possibilidade de uma interface entre os saberes dos trabalhadores com os saberes técnicocientíficos nas ações e na produção do conhecimento em saúde do trabalhador. O dispositivo central de des-disciplinamento consiste na quebra da hegemonia do discurso científico/técnico a partir da desconstrução das relações saber-poder que sustentam a base institucional/legal que abriga os saberes e as práticas dominantes do campo das relações entre saúde e trabalho.

O envolvimento direto dos trabalhadores nas ações em Saúde do Trabalhador possibilitaria uma inversão das relações de poder e a busca do desdisciplinamento, o qual pode ser pensado conjuntamente ao movimento interdisciplinar no enfrentamento/confluência dos três eixos do saber que compõem o campo, ou seja, as ciências da saúde, as ciências exatas e as ciências humanas. O campo da saúde é representado principalmente pela Medicina, pela Enfermagem e pela Psicologia ${ }^{2}$ (de introdução tardia no campo da saúde no que se refere à saúde dos trabalhadores), tendo passado a contar ainda, nos últimos anos, com a participação da fisioterapia, da fonoaudiologia, da terapia ocupacional e da Educação Física ${ }^{3}$. O campo das ciências exatas, por sua vez, é representado basicamente pelas Engenharias, pela ergonomia ${ }^{4}$ e pelas disciplinas técnicas de apoio ao instrumental tecnológico de controle dos ambientes de trabalho e do suporte de laboratório. Por sua vez, o campo das ciências humanas é composto pelas abordagens da Antropologia/ Sociologia e do serviço social (e talvez da Administração de Recursos Humanos, embora esta esteja mais próxima do que se denomina ciências sociais aplicadas), contemplando, ainda, a abordagem jurídica.

Todos esses campos são conflituosos e possuem divisões internas que apresentam maior proximidade com os interesses do Capital ou com os interesses dos trabalhadores. A confluência desses campos possibilitaria a quebra da hegemonia de um determinado saber sobre o outro e o debate entre as diferentes formas de se compreender o mundo e as relações entre saúde e trabalho. Entretanto, como afirmamos 
acima, postulamos que essa subversão das formas dominantes de explicar as relações entre os processos saúde-doença e o trabalho decorrem não somente do conflito entre os saberes, mas, fundamentalmente, das disputas políticas que lhes são simultâneas.

A visibilidade ou a invisibilidade das formas de adoecimento no trabalho, os critérios impostos pela legislação e pela ciência no estabelecimento das relações causais entre o trabalho e os modos de sofrimento, bem como a valorização de algumas formas em detrimento de outras, dependem das relações de poder que configuram os usos dos saberes disciplinares e da lógica epistemológica que Ihes dá sentido, coesão e coerência, sustentando-os no campo institucional/legal.

As confluências e disputas dos diferentes campos de saber, sobretudo a partir da introdução das ciências humanas, desestabilizaram a parceria entre a lei e a Medicina que sustentou uma forma de dominação particular nesse campo. Entretanto, a base epistemológica que consolidou a divisão das disciplinas no final do século XIX tem uma origem positivista comum. As ciências humanas talvez tenham sido aquelas que possibilitaram estabelecer a crítica mais contundente sobre o resultado da divisão disciplinar do conhecimento. Contudo, mantemos nossa posição de que a crítica interna ao conhecimento (entre os técnicos dos diversos campos do saber) não é suficiente para produzir o desdisciplinamento dos objetos e das práticas, pois a ação política dos trabalhadores é essencial para a transformação da relação de dominação do Capital sobre o Trabalho no que se refere à saúde dos trabalhadores.

A introdução do saber dos trabalhadores permite a construção de uma matriz de confronto com o discurso científico, obrigando, por outra via, a uma desconstrução de conceitos e de ideias preconcebidos e naturalizados pelas formas dominantes de se fazer ciência. Tal postura não implica uma visão romântica do saber dos trabalhadores, mas o resgate do princípio de não delegação (construído nas discussões relativas à saúde pelo movimento operário italiano dos anos 60 para a qual contribuiu Ivar Oddone) e a afirmação da indissociabilidade entre o campo da política e o da ciência. O conceito de biopoder, explorado por Foucault (1997) ao demonstrar a forma como a ciência (através das ações do Estado) é utilizada como forma de controle da vida dos indivíduos e das populações (dentro de uma perspectiva normalizadora), é essencial para compreendermos a indissociabilidade entre ciência e política, entre saber e poder.

O processo saúde-doença não pode ser analisado fora do contexto no qual acontece, assim como não pode ser considerado excluindo o sujeito que sofre. Os processos de subjetivação estão intrinsecamente associados ao trabalho, uma vez que o trabalho é o suporte central de manutenção da vida e de significação do eu no coletivo.

A forma como os indivíduos vivem, sofrem e/ ou sublimam no trabalho está intimamente associada ao valor moral atribuído ao trabalho. O adoecer no trabalho, assim como a capacidade de se superar os limites impostos pela doença, são dependentes da relação construída socialmente entre os sujeitos e o trabalho, ou seja, são atravessados pelos modos de subjetivação.

Quando nos referimos aos modos de subjetivação, não estamos pensando somente na produção da subjetividade dos trabalhadores que adoecem ou se acidentam no trabalho, mas também na subjetividade dos/as médicos/as, enfermeiros/as, psicólogos/ as, fisioterapeutas, fonoaudiólogos, terapeutas ocupacionais, educadores/as, engenheiros/ as, advogados/as, juízes/as, técnicos/as de segurança, assistentes sociais, sociólogos/ 
as, economistas e administradores/as que tratam da questão e que fazem funcionar os diversos setores do serviço público, de escritórios e empresas, e que, dessa maneira, influenciam as formas de atribuição de sentido às vivências daqueles trabalhadores.

Ao analisarmos o processo de implantação dos programas da Saúde do Trabalhador no Brasil, fica evidente que o País ainda não conseguiu romper uma forma hegemônica de compreensão da saúde centrada no corpo e nas modalidades impostas pela regulação legal do adoecimento (baseada na relação causa-efeito direta a partir de critérios objetivos de identificação do agente causador), a qual desconsidera o sofrimento como um objeto complexo. Na análise que segue, tentaremos mostrar como essa forma de produção da (não) compreensão da relação Saúde Mental e trabalho atravessa os principais documentos que sustentam a política de Saúde do Trabalhador no Brasil, quais sejam, os relatórios das Conferências Nacionais de Saúde do Trabalhador.

\section{Saúde Mental na saúde do trabalhador}

Nosso objetivo, ao analisar os relatórios das conferências nacionais, é destacar como a Saúde Mental, como tema, aparece no discurso da saúde do trabalhador, complementando trabalho anterior publicado nesta revista (Ramminger \& Nardi, 2007).

A análise dos documentos foi guiada pela perspectiva genealógica de Foucault, que a entende como a possibilidade de constituir um saber histórico das lutas, da forma como a verdade é produzida em diferentes épocas, sendo que, "por verdade, não quero dizer 'o conjunto das coisas verdadeiras a descobrir ou a fazer aceitar', mas o 'conjunto das regras segundo as quais se distingue o verdadeiro do falso e se atribui, ao verdadeiro, efeitos específicos de poder" (Foucault, 1999, p. 13). Sendo assim, o objetivo da pesquisa genealógica é analisar como se constroem as possibilidades de emergência dos discursos/ saberes em determinados jogos de dominação e resistência que configuram a legitimidade da verdade para cada período.

\section{Conferência Nacional de Saúde do Trabalhador: Medicina do Trabalho X saúde do trabalhador}

A I Conferência Nacional de Saúde do Trabalhador, realizada em dezembro de 1986, teve, como principal marca, a formulação de conteúdos para a Política Nacional de Saúde do Trabalhador, os quais foram incorporados na Constituição Federal de 1988 e na Lei no 8080, de 1990. Já na sua forma de organização, fica evidente o esforço para quebrar a hegemonia do Ministério do Trabalho (historicamente mais ligado aos interesses do Capital) na discussão da Saúde do Trabalhador e levá-la efetivamente para o campo da saúde. Na falta de uma definição mais clara do Ministério da Saúde, quem coordena a organização dessa Conferência é o Centro de Estudos da Saúde do Trabalhador e Ecologia Humana, da Escola Nacional de Saúde Pública - Cesteh/Fiocruz. Os empresários foram os principais ausentes nos processos de discussão e deliberação, representando somente $1 \%$ dos delegados participantes.

Em seu relatório final (Brasil, 1986), a conferência estabeleceu o consenso de que a saúde dos trabalhadores extrapola os limites da saúde ocupacional e introduziu o conceito ampliado de saúde, afirmando a necessidade de se revisar a legislação e de ampliar as listas de doenças ocupacionais com uma legislação única que assegure os mesmos direitos a todos, independentemente de trabalharem na área urbana, rural, pública ou privada. A 
conferência enfatiza, em vários momentos, a necessidade da criação de um Sistema Único de Saúde, com o descredenciamento da rede privada e a criação de programas específicos de atendimento ao trabalhador. Tal sistema deveria contar, ainda, com uma política de recursos humanos que reorientasse a formação e a utilização dos trabalhadores da área de saúde pública, com remuneração digna.

Em relação à fiscalização, o relatório sugeriu que as ações sejam responsabilidade do SUS, com a participação dos trabalhadores, evitando-se que os profissionais que realizam a fiscalização tenham vínculos com a empresa fiscalizada. Da mesma forma, criticou a subordinação dos SESMTs (Serviços de Engenharia, Segurança e Medicina do Trabalho) às empresas e sugeriu que os mesmos fiquem sob o controle dos sindicatos ou das associações de classe. O relatório levantou a necessidade do envolvimento cada vez maior dos sindicatos na questão da saúde como objetivo de luta, e ressaltou a importância da organização dos trabalhadores para a abertura de novos espaços. Em seu último eixo - Política Nacional de Saúde dos Trabalhadores estabeleceu os direitos básicos de saúde do trabalhador.

\section{Il Conferência Nacional de Saúde do Trabalhador: construindo uma política de saúde do trabalhador}

\footnotetext{
A Il Conferência Nacional de Saúde do Trabalhador foi realizada oito anos depois, sob a égide da Constituição Federal e da Lei Orgânica da Saúde, nas quais está incorporada a atenção à saúde dos trabalhadores como papel do SUS. Seu tema central foi construindo uma política de saúde do trabalhador, e os temas complementares, desenvolvimento, meio ambiente e saúde,
}

cenário de Saúde do Trabalhador de 1986 a 1993 e perspectivas e estratégias de avanço na construção da política nacional de saúde do trabalhador.

As principais marcas dessa conferência, segundo seu relatório, foram a definição da unificação das ações de Saúde do Trabalhador no SUS e a discussão das dimensões políticas, sociais, econômicas, técnicas e gerenciais dessa política pública. Compuseram o evento quatro mesas redondas e oito painéis específicos, entre eles, um sobre Saúde Mental (Brasil, 1994).

O painel específico sobre Saúde Mental foi coordenado por Leny Sato, que representou o DIESAT - Departamento Intersindical de Estudos e Pesquisas de Saúde e dos Ambientes de Trabalho. Em suas considerações iniciais, Sato avaliou que já existia, há várias décadas, o reconhecimento internacional de que determinadas formas de organização do trabalho, produtos químicos e novas tecnologias são nocivas à Saúde Mental. No entanto, foi apenas na década de 80 que os pesquisadores brasileiros da área de Saúde Mental puderam inserir suas contribuições no campo da Saúde do Trabalhador e ampliar as ações tanto dos serviços públicos como dos sindicatos. Nessa época, por exemplo, foram realizadas as primeiras pesquisas pelo DIESAT, a partir de demandas sindicais, com os trabalhadores bancários (1985) e metroviários (1986), visando a conhecer os efeitos à Saúde Mental provocados pelas condições de trabalho, especialmente o trabalho automatizado.

Embora tenha ressaltado que a discussão Saúde Mental e trabalho não constitui tema prioritário para várias categorias de trabalhadores, Sato avaliou que, após oito anos da realização da I Conferência, maior número de sindicatos de trabalhadores atuam em defesa da saúde dos trabalhadores. Para ela, essa luta implica detectar as condições de trabalho geradoras de 
5 A RENAST é

composta por cerca de 200 Centros

Estaduais e Regionais de Referência em Saúde do Trabalhador (Cerest) - responsáveis pelo apoio às ações de promoção, prevenção, curativas e de reabilitação - e por mais de 1000 unidades de saúde que identificam, investigam e notificam os casos de doenças, agravos e/ou acidentes relacionados ao trabalho (Rede Sentinela) (Portaria no 2728/09). agravos à saúde, aprofundar o conhecimento técnico desses agravos (o que inclui o conhecimento dos trabalhadores) e delinear estratégias de ação. Sendo assim, "uma das principais fontes de dados sobre a relação saúde e trabalho é aquela fornecida pela subjetividade, pelo conhecimento prático que os trabalhadores têm sobre essa relação".

Na exposição de Pérsio Dutra, também pelo DIESAT, foi reforçado o entendimento de que a Saúde Mental do trabalhador não é uma preocupação generalizada do movimento sindical. O palestrante destacou que, em geral, os problemas de sofrimento mental chegam aos sindicatos travestidos sob a forma de manifestações orgânicas ou de problemas funcionais com a chefia e com a organização do trabalho em geral, ou ainda, como atritos nas relações interpessoais fora do trabalho.

Ele retomou as duas pesquisas citadas por Sato e ressaltou que tanto os bancários como os metroviários tiveram uma grande coincidência no perfil de sofrimento mental, de acordo com o ritmo e o objetivo do serviço e a introdução de tecnologias de controle (automação), e concluiu que uma questão emergente e fundamental é o controle do processo produtivo, do seu objetivo e da tecnologia aplicada a ele. Com isso, afirmou a necessidade do reconhecimento do nexo da causalidade entre o trabalho e sua organização no aparecimento dos agravos mentais, e minimizou a prática recorrente de localizar o problema mental nas características individuais de cada um ao negar sua relação com as condições de trabalho e de vida.

Dutra refletiu sobre as dificuldades do trabalhador com sofrimento mental ao procurar tratamento e reconhecimento do nexo com o trabalho. Para ele, os médicos das empresas nunca irão estabelecer tal nexo, o sindicato está despreparado para defendêlo, os profissionais da rede pública também têm dificuldade em associar seu quadro e, quando este é reconhecido e o trabalhador é enviado ao INSS - Instituto Nacional do Seguro Social, encontrará alguém que dirá que seu problema é individual e nada tem a ver com a organização e as condições de seu trabalho.

Além desse ponto, o relatório apresentou outros itens específicos sobre a Saúde Mental, como a necessidade da contemplação de aspectos de Saúde Mental no reconhecimento de doenças profissionais (p. 33) e a sugestão de que as empresas públicas e privadas mantenham programas educativos em relação ao alcoolismo (p. 45).

\section{Conferência Nacional de Saúde do Trabalhador: trabalhar, sim, adoecer, não!}

A III CNST foi realizada mais de 10 anos após a II CNST, sendo que pela primeira vez foi convocada em conjunto pelos Ministérios da Saúde, do Trabalho e Emprego, e da Previdência Social, como resultado da tentativa de integrar as ações direcionadas à Saúde do Trabalhador brasileiro. Essa intenção já está expressa na Portaria Interministerial no 800/05, lançada um pouco antes da realização da conferência, que coloca em consulta pública a Política Nacional sobre Saúde e Segurança do Trabalho, elaborada pelos três Ministérios.

Uma das principais atividades da III CNST foi justamente discutir a política intersetorial proposta bem como a integração e a implantação da RENAST - Rede Nacional de Atenção Integral à Saúde do Trabalhador, instituída em $2002^{5}$.

Sob a insígnia trabalhar, sim, adoecer, não, a conferência propõe três eixos temáticos, em forma de perguntas: Como garantir a integralidade e a transversalidade da ação do 
Estado em saúde dos(as) trabalhadores(as)? Como incorporar a saúde dos(as) trabalhadores(as) nas políticas de desenvolvimento sustentável no País? Como efetivar e ampliar o controle social em saúde dos(as) trabalhadores(as)? Sob esses eixos, apresentam-se os 17 textos de apoio sobre temas diversos, destacando-se a avaliação de vinte anos de história e trajetória da saúde do trabalhador, a constituição da RENAST, a vigilância (epidemiológica e ambiental) e as propostas do INSS (nexo técnico-epidemiológico previdenciário - NTEP e perfil profissiográfico previdenciário - PPP), buscando desacomodar o paradigma da Medicina do Trabalho fortemente presente na Previdência. Destaca-se que a relação entre Saúde Mental e trabalho não foi tema de nenhum texto (Brasil, 2005).

Foram aprovadas 362 resoluções, sendo que apenas 10 delas (nos 31, 54, 78, 86, 139, 144, 151, 155,156 e 253) versam, ainda que de forma incipiente, sobre o tema Saúde Mental e trabalho. Destas, destacam-se medidas relacionadas ao assédio moral no trabalho ( $\left.\mathrm{n}_{\mathrm{S}} 54,78,151,155\right)$, duas tratam da garantia à atenção integral à saúde, incluindo Saúde Mental (nōs 31 e 156), e as demais sugerem que "crimes contra a higidez física e mental do trabalhador" integrem o Código Penal (no 86), apóiam a inserção de portadores de transtornos mentais no mundo do trabalho (n⿳⺈ 139); defendem métodos e técnicas de prevenção aos desconfortos físicos e mentais no trabalho (no 144) e destacam os temas que devem ser priorizados nos estudos e pesquisas, entre eles as doenças (inclusive mentais) relacionadas ao uso de agrotóxicos (no 253) (Brasil, 2006).

Concordamos com a afirmação de Lacaz de que as resoluções da III CNST ora ratificam resoluções da II CNST, ora expressam um retorno às formulações da saúde ocupacional. Para ele, o conservadorismo presente nas resoluções é fruto da "fragilidade atual do movimento sindical, aliada à postura pouco engajada da Academia e ao desenvolvimento de políticas públicas reducionistas" (Lacaz, 2007, p. 764).

\begin{tabular}{|c|c|c|c|}
\hline Conferência/ano & $\begin{array}{l}\text { Contexto/ } \\
\text { participantes }\end{array}$ & Eixos principais & Saúde Mental \\
\hline $\begin{array}{l}\text { I Conferência } \\
\text { Nacional de } \\
\text { Saúde do Trabal- } \\
\text { hador } \\
\text { (1986) }\end{array}$ & $\begin{array}{l}\text { Conferência Nacional } \\
\text { de Saúde (março de } \\
\text { 1986) } \\
399 \text { delegados, } \\
\text { sendo } \\
46 \% \text { representantes } \\
\text { de trabalhadores, } \\
40 \% \text { do } \\
\text { Estado, } 9 \% \text { das } \\
\text { universidades e } 5 \% \\
\text { de } \\
\text { outras categorias }\end{array}$ & $\begin{array}{l}\text { 1. Diagnóstico da } \\
\text { situação de saúde e } \\
\text { segurança dos } \\
\text { trabalhadores } \\
\text { 2. Novas alternativas } \\
\text { de atenção à saúde } \\
\text { dos trabalhadores } \\
\text { 3. Política Nacional de } \\
\text { Saúde e Segurança dos } \\
\text { Trabalhadores }\end{array}$ & $\begin{array}{l}\text { Em sua última } \\
\text { temática, aparece uma } \\
\text { clara preocupação } \\
\text { com o portador de } \\
\text { deficiência, que deve } \\
\text { ter acesso ao trabalho, } \\
\text { acompanhamento } \\
\text { médico, psicológico e } \\
\text { social, e aposentadoria } \\
\text { especial com } 25 \text { anos de } \\
\text { trabalho. } \\
\text { Sugere, ainda, a } \\
\text { substituição do atestado } \\
\text { de sanidade física e } \\
\text { mental por atestado de } \\
\text { aptidão para a função. }\end{array}$ \\
\hline
\end{tabular}


1 A Política

Nacional de Saúde do Trabalhador determina seis diretrizes para todas as ações em Saúde do

Trabalhador desenvolvidas pelo SUS: atenção integral da saúde dos trabalhadores (promoção, vigilância e assistência), articulação intra e intersetorial, estruturação da Rede de Informações em Saúde do Trabalhador, apoio ao desenvolvimento de estudos e pesquisas, desenvolvimento e capacitação de recursos humanos e participação da comunidade na gestão das ações.

\begin{tabular}{llll}
\hline Conferência/ano & $\begin{array}{l}\text { Contexto/ } \\
\text { participantes }\end{array}$ & Eixos principais & Saúde Mental \\
\end{tabular}

$\begin{array}{ll}\text { II Conferência } & \text { Constituição } \\ \text { Nacional } & \text { Federal de } \\ \text { de Saúde do } & \text { 1988 e Lei } \\ \text { Trabalhador } & \text { Orgânica da } \\ \text { (1994) } & \text { Saúde, de 1990. } \\ & \text { IX Conferência } \\ & \text { Nacional de Saúde, } \\ & \text { de } \\ & 1992\end{array}$

560 delegados, dos quais $65,7 \%$ representantes dos trabalhadores, $31,1 \%$, do Estado, e 3,2\% dos empregadores

Tema:

Construindo uma política de saúde do trabalhador.

Temas complementares: 1. desenvolvimento, meio ambiente e saúde 2. cenário da Saúde do Trabalhador de 1986 a 1993 e perspectivas 3. estratégias de avanço na construção da Política Nacional de Saúde do Trabalhador

\section{Conferência \\ Nacional de \\ Criação da RENAST (2002)} Saúde do Trabalhador

(2005)

Política Nacional de Segurança e Saúde do Trabalhador (Portaria Interministerial n요이잉

XII CNS (2003, que indicou a necessidade de realização da conferência)

Política Nacional de Saúde do Trabalhador (Portaria no1125/05) ${ }^{1}$

Convocação conjunta de três Ministérios: da Saúde, do Trabalho e Emprego e da Previdência Social
Tema:

trabalhar, sim, adoecer, não! Eixo I - Como garantir a integralidade e a transversalidade da ação do Estado em saúde dos(as) trabalhadores(as)? Eixo II - Como incorporar a saúde dos(as) trabalhadores(as) nas políticas de desenvolvimento sustentável? Eixo III - Como efetivar e ampliar o controle social em saúde dos(as) trabalhadores(as)?
Um dos painéis específicos foi sobre Saúde Mental e trabalho, onde se fez uma avaliação da relação entre Saúde Mental e trabalho no Brasil. No relatório final, foi apontada a necessidade de se contemplarem aspectos de Saúde Mental no reconhecimento das doenças profissionais, a inclusão dos profissionais de serviço social e de Psicologia nas equipes de saúde do trabalhador, e ainda, que, na vigilância em saúde do trabalhador, sejam consideradas as relações profissionais e institucionais a que estão submetidos os profissionais de saúde, inclusive os de Saúde Mental.

O relatório apresenta 362 resoluções, divididas entre os três diferentes eixos. Destas, apenas 10 citam a relação entre Saúde Mental e trabalho, destacando-se as medidas relacionadas ao assédio moral no trabalho.

Quadro 1. Saúde Mental nas Conferências Nacionais de Saúde do Trabalhador 


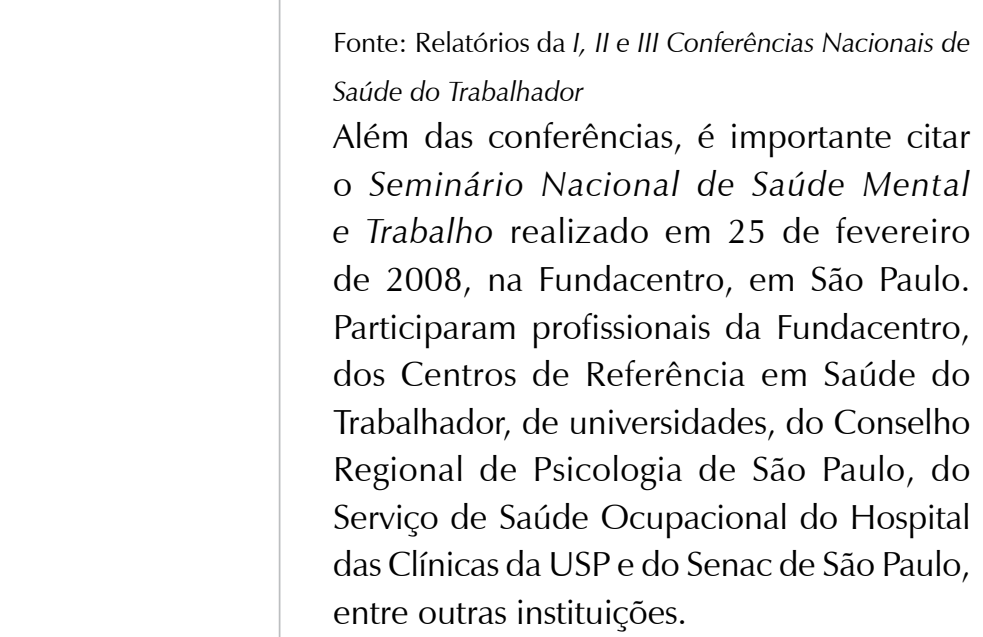

Nessa reunião, foi unânime a manifestação da necessidade de se construir uma rede permanente de integração e de articulação de pessoas e instituições que desenvolvam atividades relacionadas à Saúde Mental e ao trabalho, com os objetivos de se desenvolver pesquisas integradas e elaborar propostas de políticas públicas de atenção à Saúde Mental do trabalhador que abranjam desde a promoção à saúde e a prevenção de agravos até a assistência e a reabilitação profissional. Para isso, foi consenso a criação do Fórum Interinstitucional sobre Saúde Mental e Trabalho, que se propôs a realizar as seguintes atividades durante o ano 2008:

1. Propor um protocolo sobre Saúde Mental e trabalho para auxiliar a implementação da Portaria no777/2004, que determina a notificação compulsória de 11 agravos relacionados ao trabalho ao Sistema Nacional de Agravos de Notificação - SINAN ${ }^{2}$, entre os quais os transtornos psíquicos;

2. Apreciar, emitir pareceres, acompanhar e contribuir para a definição das Diretrizes de Conduta Médico-pericial em Transtorno Mental, propostas pelo INSS;

3. Criar uma rede de Saúde Mental e trabalho e um fórum virtual; outros agravos. quais o movimento sindical, para discutir e aprofundar o tema Saúde Mental e trabalho. Apesar da importância do seminário, nas práticas cotidianas, o olhar sobre os efeitos do trabalho sobre a Saúde Mental dificilmente é incorporado à lógica institucional da política de saúde do trabalhador.

Essa não incorporação se choca com as análises que apontam os efeitos perversos e crescentes do capitalismo contemporâneo, cujas consequências para a Saúde Mental dos trabalhadores, de acordo com diversos autores, seriam: o aumento do individualismo, a frouxidão do laço social, a criação de uma cultura do narcisismo, a perspectiva de uma sociedade de incertezas (Beck, Giddens \& Lash, 1997), a competição extremada e um desmantelamento das garantias de estabilidade que permitiram o planejamento de longo prazo e um pensamento direcionado para a construção do futuro, o que corrói o caráter dos trabalhadores (Sennett, 2010). Em direção semelhante, Bauman (1998) afirma que o sentimento dominante é a sensação de um novo tipo de incerteza, não limitada à própria sorte e aos dons da pessoa, mas a uma nova configuração do mundo. A maneira correta de viver neste mundo e os critérios para julgar o certo e o errado estariam indefinidos. Enriquez (1997), por sua vez, denuncia as consequências psíquicas nefastas das práticas que envolvem a gerência da estrutura estratégica (denominação do autor para as empresas moldadas de acordo com as novas formas de gestão) e que demandam um trabalhador as if (como se), ou seja, um sujeito que se adapte a qualquer forma de comportamento mais adequada para a conquista do sucesso individual. Essas análises de cunho psicossocial podem nos ajudar a entender o incremento da prevalência de depressão no mundo contemporâneo, resultado, entre outros fatores, de uma exaltação e responsabilização totalitária do indivíduo como único responsável pelo seu destino (Castel, 2009). Essa vitória do 
ideal neoliberal produz uma sensação de incapacidade que passa a ser vivida de forma solitária e leva aos altos índices de suicídio relacionados ao trabalho em diversos países, como, por exemplo, a recente crise na França, analisada por Cristhophe Dejours e Florence Bègue (2009).

\section{Considerações finais}

Ao refletirmos genealogicamente sobre as Conferências de Saúde do Trabalhador e os debates que produziram suas resoluções, percebemos que a questão do sofrimento psíquico é tratada de forma tímida, uma vez que apenas tangencia o arcabouço institucional-legal que regula a saúde dos e das trabalhadores/as no Brasil. A Saúde Mental, como tema, é apresentada nas três Conferências Nacionais de Saúde do Trabalhador, embora com ênfases distintas. Aparece de forma incipiente na I e na III Conferências, sendo que a /l Conferência Nacional de Saúde do Trabalhador foi a única que tratou da relação entre Saúde Mental e trabalho de forma mais direta, sobretudo pela influência de profissionais ligados às universidades.

Certamente, nesta breve análise, só pudemos traçar algumas pistas para a compreensão das disputas pelas formas de legitimação da verdade, no campo institucional das políticas públicas de saúde, que culminaram na redação final dos relatórios das conferências. É um processo que dá visibilidade a certos elementos e torna outros tantos invisíveis, refletindo o jogo de forças, sobretudo político, que dá forma à institucionalidade do SUS. Em que pesem importantes conquistas, os desafios, nesse processo de consolidação de políticas públicas de saúde cidadãs, ainda são imensos, mesmo que mais sutis, porque se relacionam com uma questão ética central, que diz respeito ao lugar que reservamos ao outro na forma como nos constituímos como sujeitos, ou seja, na forma como nos vemos como iguais em direitos em nossas relações cotidianas - na relação governo/ servidor, patrão-empregado, profissional de saúde-usuário, assim como nas relações mais horizontais (servidor-servidor, usuáriousuário, etc).

Não pretendemos, neste breve artigo, dar conta da complexidade das formas de produção de políticas públicas que balizam as condições e a organização do trabalho. $\mathrm{O}$ que buscamos apontar é que essas políticas devem fornecer os parâmetros para a ação de gestores/as, empresários/as e trabalhadores/as no sentido de produzir modos de trabalhar que permitam maior prazer e menor sofrimento.

Uma política de Saúde do Trabalhador que inclua o princípio da integralidade e, portanto, as questões relativas à Saúde Mental deve atentar para as configurações contemporâneas do trabalho. Estas apontam tanto os riscos de contaminação, de acidentes e das doenças do trabalho clássicas como as formas de assédio, as pressões para produção, a precarização, a ameaça de desemprego (e a vivência dessa situação), a responsabilização individual, as avaliações perversas e as formas de reconhecimento que, ao produzirem as condições psicossociais de trabalho, podem fomentar a transformação dos desafios do cotidiano em saúde ou da construção de defesas rígidas que levam ao adoecimento. Assim, quando pensamos sobre políticas públicas nesse campo, devemos refletir sobre o jogo democrático no qual todos/as estamos envolvidos e sobre a atuação do Estado na forma como conduz a vida pública e as condições de vida e trabalho de seus/suas cidadãos/ãs. 
Henrique Caetano Nardi

Médico, Doutor em Sociologia pela Universidade Federal do Rio Grande do Sul e Pós-Doutor na EHESS de Paris. Atualmente é Professor Associado do Departamento e da Pós-Graduação em Psicologia Social e Institucional Universidade Federal do Rio Grande do Sul.

E-mail:hcnardi@gmail.com

Tatiana Ramminger

Psicóloga, Doutora em Saúde Pública pela Escola Nacional de Saúde Pública Sérgio Arouca da Fundação Oswaldo Cruz. Atualmente é Professora Adjunta do Departamento de Psicologia do Instituto de Ciências Humanas e Sociais de Volta Redonda - Universidade Federal Fluminense.

E-mail: tatiramminger@gmail.com

Endereço para envio de correspondência:

Rua Ramiro Barcelos 2600

Porto Alegre - Rio Grande do Sul - RS - Brasil. CEP: 90035-003

Recebido 14/10/2010, 1a Reformulação 24/10/2011, Aprovado 10/1/2012. 


\section{Referências}

Baremblitt, G. (1998). Compêndio de Análise Institucional. Belo Horizonte: Instituto Félix Guattari.

Bauman, Z. (1998). O mal-estar da pós-modernidade. Rio de Janeiro: Jorge Zahar Editor.

Beck, U., Giddens, A., \& Lash, S. (1997). Modernização reflexiva: política, tradição e estética na ordem social moderna. São Paulo: Editora da Unesp.

Brasil. Ministério da Saúde. (1986). I Conferência Nacional de Saúde do Trabalhador. Relatório Final. Brasília, DF: Ministério da Saúde.

Brasil. Ministério da Saúde. (1994). II Conferência Nacional de Saúde do Trabalhador. Relatório Final. Brasília, DF: Ministério da Saúde.

Brasil. Ministério da Saúde. (2005). III Conferência Nacional de Saúde do Trabalhador: Coletânea de textos. Brasília, DF: Ministério da Saúde.

Brasil. Ministério da Saúde. (2006). III Conferência Nacional de Saúde do Trabalhador. Resoluções. Brasília, DF: Ministério da Saúde.

Bhabha, H. (1998). O local da cultura. Belo Horizonte: Ed. UFMG.

Castel, R. (2009). La montée des incertitudes: Travail, protections, statut de l'individu. Paris: Seuil.

Cohn, A. (1980). A previdência social e o processo político no Brasil. São Paulo: Moderna.

Dejours, C., \& Bègue, F. (2009). Suicide et travail : Que faire? Paris: PUF.

Dias, E. C. (1994). A atenção à saúde dos trabalhadores no setor saúde no Brasil (SUS): realidade, utopia ou fantasia? Tese de doutorado, Universidade Estadual de Campinas, Campinas, SP.

Enriquez, E. (1997). O indivíduo preso na armadilha da estrutura estratégica. Revista de Administração de Empresas, 37(1), 18-29.

Foucault, M. (1994). La poussière et le nuage. In M. Foucault, Dits et écrits (pp. 10-19). Paris : Gallimard.

Foucault, M. (1997). História da Sexualidade I: A vontade de saber. Rio de Janeiro: Graal.
Foucault, M. (1999). Verdade e poder. In R. Machado (Org.), Microfísica do poder (pp. 1-14). Rio de Janeiro: Ed. Graal.

Lacaz, F. A. C. (2007). O campo saúde do trabalhador: resgatando conhecimentos e práticas sobre as relações trabalho-saúde. Cadernos de Saúde Pública, 23(4), 757-766.

Lemke, T. (2001). « The birth of bio-politics »: Michel Foucault's lecture at the Collège de France on neo-liberal governmentality. Economy \& Society, 30(2), 190-207.

Luz, M. T. (1984). Saúde e instituições médicas no Brasil. In R.Guimarães. Saúde e medicina no Brasil (pp. 157-174). Rio de Janeiro: Graal.

Pecheny, M., \& Dehesa, M. (2009). Sexualidades y políticas en América Latina: Un esbozo para la discusión. Recuperado em 12 de fevereiro de 2010 de http://www.sxpolitics.org/pt/wpcontent/uploads/2009/10/sexualidades-y-politicas-en-americalatina-rafael-de-la-dehesa-y-mario-pecheny.pdf

Possas, C. (1989). Saúde e trabalho. São Paulo: Hucitec.

Ramminger, T., \& Nardi, H. C. (2007). Saúde Mental e saúde do trabalhador: análise das conferências nacionais brasileiras. Psicologia: Ciência e Profissão, 27(4), 680-693.

Selligmann-Silva, E. (1994). Desgaste mental no trabalho dominado. Rio de Janeiro: Ed. da UFRJ/Cortez.

Sennett, R. (2010). A corrosão do caráter: consequências pessoais do trabalho no novo capitalismo. Rio de Janeiro: Record.

Teixeira, S. F. (1989). Reforma sanitária: em busca de uma teoria. São Paulo: Cortez/Abrasco.

Vilaça-Mendes, E. (1993). Distrito sanitário. São Paulo: Hucitec. 